\title{
Measurement of rotational temperature at Kolhapur, India
}

\author{
G. K. Mukherjee and N. Parihar \\ Indian Institute of Geomagnetism, New-Panvel (W), Navi Mumbai 410 218, India
}

Received: 3 October 2003 - Revised: 14 May 2004 - Accepted: 25 May 2004 - Published: 23 September 2004

Part of Special Issue "Equatorial and low latitude aeronomy"

\begin{abstract}
Measurements of the hydroxyl rotational temperature for the $(8,3)$ Meinel band have been reported from the observations of the ratio of the relative intensities of $\mathrm{P}_{1}(2)$ and $\mathrm{P}_{1}(4)$ lines of the $\mathrm{OH}(8,3)$ band at Kolhapur $\left(16.8^{\circ} \mathrm{N}, 74.2^{\circ} \mathrm{E}\right.$, dip lat. $\left.10.6^{\circ} \mathrm{N}\right)$ in India during the period 1 November 2002-29 April 2003 using tilting-filter photometers. Mean values of rotational temperature have been computed for 60 nights. The monthly mean value of temperature lies in the range $194( \pm 11)-208( \pm 18) \mathrm{K}$. The mean rotational temperature obtained from all the measurements was found to be $202 \pm 15 \mathrm{~K}$. The results agree with other lowlatitude measurements of rotational temperature using photometric airglow techniques. Quasi-periodic fluctuations with a period of about one to two hours have been prominent on many nights. Furthermore, the results show the general agreement between observations and model (MSIS-86) predictions.
\end{abstract}

Key words. Atmospheric composition and structure (middle atmosphere - composition and chemistry; pressure, density and temperature) - History of geophysics (atmospheric sciences)

\section{Introduction}

In order to understand the upper atmospheric variability it is essential to measure accurately the temperature and density profiles in the mesospheric region.

The rotational-vibrational bands $(550 \mathrm{~nm}-4.4 \mu \mathrm{m})$ of hydroxyl in the night airglow have been discovered by Meinel (1950). A large number of observations of the $\mathrm{OH}$ intensity and rotational temperature have been made using ground based photometers, scanning spectrophotometers, rockets and satellites (Sivjee et al., 1972; Meriwether, 1974; Takahashi et al., 1974, 1984, 1999; Takahashi and Batista, 1981; Abreu and Yee, 1989). Using different vibrational bands, these observations made attempts to find diurnal and

Correspondence to: G. K. Mukherjee

(gkm@iigs.iigm.res.in) seasonal variations in $\mathrm{OH}$ intensity and rotational temperature at low-, mid- and high-latitude regions. However, the work done in the low-latitude region is extremely rare.

$\mathrm{OH}$ emissions follow peculiar profiles according to their source constituents. The rotational temperature of this molecular emission is the excitation temperature which is derived from the distribution of population in the rotational levels of the upper vibrational state (v). For the excited $\mathrm{OH}^{*}$ molecule, radiative lifetime falls between extremes of $3 \mathrm{~ms}$ for $\mathrm{v}=9$ vibrational state to $63 \mathrm{~ms}$ for $\mathrm{v}=1$ state. On the contrary, the collision frequencies within the mesosphere gives inter collision time $0.1 \mathrm{~ms}$ sufficient for thermalization of the emitting $\mathrm{OH}$ molecules. It is thus assumed that the vibrationally excited $\mathrm{OH}$ molecules are in thermal equilibrium and hence the rotational temperature determined spectroscopically may be taken to be the neutral temperature of the emitting region.

The Meinel band hydroxyl emits radiation so that the excited hydroxyl radicals $\left(\mathrm{OH}^{*}\right)$ immediately transfer to the lower stable energy level. $\mathrm{OH}^{*}$ is considered to be produced by the following reactions:

$$
\begin{aligned}
& \mathrm{O}_{3}+\mathrm{H} \rightarrow \mathrm{OH}^{*}(\mathrm{v} \leq 9)+\mathrm{O}_{2} \\
& \mathrm{HO}_{2}+\mathrm{O} \rightarrow \mathrm{OH}^{*}(\mathrm{v} \leq 6)+\mathrm{O}_{2} \\
& \mathrm{O}_{2}^{*}+\mathrm{H} \rightarrow \mathrm{O}+\mathrm{OH}^{*} \\
& \mathrm{OH}^{*}(\mathrm{v}) \rightarrow \mathrm{OH}^{* *}\left(\mathrm{v}^{\prime}\right)+\mathrm{h} v(550 \mathrm{~nm}-4.4 \mu \mathrm{m}),
\end{aligned}
$$

where ${ }^{*}$ and ${ }^{* *}$ indicate that the molecule is in the state of excitation and $\mathrm{v}$ and $\mathrm{v}^{\prime}$ indicate the order of states of the molecule. The peak altitude of the $\mathrm{OH}$ emission layer was observed to be $\sim 86 \mathrm{~km}$ with a layer width of $\sim 11 \mathrm{~km}$ (Kubota et al., 1999).

The rotational temperature is believed to provide a reasonable estimate of the temperature in the $80-100 \mathrm{~km}$ altitude range. The airglow technique is a simple inexpensive method of measurement of rotational temperature. Long-term temperature observations are particularly useful in the detection of climate changes of terrestrial (green house effects) or extraterrestrial (solar activity) origin. Using a self-consistent 
model of the global mean structure of the mesosphere, thermosphere and ionosphere, Roble and Dickinson (1989) have reported that variations in lower atmospheric concentrations of $\mathrm{CO}_{2}$ and $\mathrm{CH}_{4}$ were found to have a profound influence on the global mean thermal and compositional structure of the mesosphere and thermosphere.

The observations of nightglow intensity variations of the $\mathrm{OH}(8,3)$ band emission were carried at Kolhapur $\left(16.8^{\circ} \mathrm{N}\right.$, $74.2^{\circ} \mathrm{E}$ ) in the zenith on clear, moonless nights during the period November 2002-April 2003. The primary objective was to determine the diurnal and seasonal variation of the rotational temperature and validate it with other low-latitude measurements.

The $\mathrm{OH}(8-3)$ band was commonly used for hydroxyl temperature measurements in past years for high- and low- latitude regions (Agashe et al., 1977; Takahashi et al., 1974, 1999; Takahashi and Batista, 1981; Myrabo, 1984; Sivjee and Hamwey, 1987). The hydroxyl airglow $\mathrm{OH}(8-3)$ band measurements have also been made in Antarctica (Stubbs et al., 1983; Williams, 1996). In order to understand this spectral region, with the possibility of recovering more accurate information on rotational temperatures at low latitude region, this study was undertaken.

Abreu and Yee (1989) have presented results from a study of diurnal and seasonal variations in the nighttime $\mathrm{OH}(8,3)$ emission at low latitudes using data from the AE-E satellite. Diurnal variations of $\mathrm{OH}$ emission intensity have been studied by many observers (Wiens and Weill, 1973; Takahashi et al., 1977; Abreu and Yee, 1989). Generally, most of them have found out the nocturnal variation of $\mathrm{OH}$ intensity maximizes early in the night and decreases towards dawn. The decrease in $\mathrm{OH}$ intensity from sunset to sunrise was explained by photochemical models as being due to decreasing concentrations of odd hydrogen and odd oxygen as a result of the absence of photolysis of $\mathrm{O}_{2}$ and $\mathrm{H}_{2} \mathrm{O}$ (Abreu and Yee, 1989). There is a great variability in the diurnal behaviour in low- and mid-latitudes. There are four different types of nocturnal variations of temperature as observed by Agashe et al. (1989) at a low-latitude station, Pune $\left(18^{\circ} \mathrm{N}, 73^{\circ} \mathrm{E}\right)$ in India. The monthly mean temperature of the mesopause region over Pune was found to be $195 \pm 10 \mathrm{~K}$. Also, the rotational temperature was found to be higher in winter than in summer.

Airborne and ground-based observations of $(7,2)$ and $(8-$ 3) bands of $\mathrm{OH}$ have been made using a one-meter scanning spectrophotometer by Sivjee et al. (1972). The rotational temperature derived from the $\mathrm{P}_{1}$ and $\mathrm{P}_{2}$ branches of the $\mathrm{OH}(8,3)$ spectrum were varying between 150 to $200 \mathrm{~K}$. Watanabe and Nakamura (1981) reported the rocket measurements of $\mathrm{O}_{2}$ atmospheric band and $\mathrm{OH}$ Meinel Bands in the airglow at $31^{\circ} \mathrm{N}$ latitude to study the composition of the airglow emitting layer. The $\mathrm{OH}(6,2)$ band was monitored at Davis in Antarctica (Greet et al., 1998) during 1990 using a Czerny-Turner spectrometer. An average temperature of $221 \pm 2 \mathrm{~K}$ was obtained from a selected data set of 104 spectra.

\section{Instrumentation and theory}

The measurements were made using two tilting-filter photometers. The basic objective of the design of the photometers was to sufficiently separate the signal due to airglow from the background emission. In this mechanism both signal and background emissions were allowed to pass through the filter in normal and tilted modes. In the latter case, passband of the filter is shifted to the lower wavelength side so that only the background light is transmitted. The difference between the two measurements would give rise to a signal at a given instant (Mukherjee and Dyson, 1992). The different values for the wavelength of the individual lines of the hydroxyl $(8,3)$ band appear in the literature (Stubbs et al., 1988). The central wavelengths $(731.64 \mathrm{~nm}$ and $736.95 \mathrm{~nm}$ ) of the filters were chosen to measure the intensities of the $\mathrm{P}_{1}(2), \mathrm{P}_{1}(4)$ lines of this band (Stubbs et al., 1983). The ratio between these two lines was used to obtain the rotational temperature assuming thermal equilibrium. The tilting-filter photometer measures the column intensities of two selected components against the background produced by narrow continuum and scattered light. The passband of the filters (manufactured by Andover Corporation, U.S.) used were $0.25 \mathrm{~nm}$. Filters have peak transmission $\sim 65 \%$ and aperture diameter $5 \mathrm{~cm}$. An EMI 9658B photo multiplier tube cooled to $-30^{\circ} \mathrm{C}$ was used as the detector. An application of a tilting-filter photometer for the ground-based measurements of the atmospheric temperature has been described earlier by Meriwether (1975). Schaffer and Fastie (1972) also used a similar method for temperature measurement using a tilting-filter photometer in a rocket.

Theoretically, the intensities of the lines are related to the rotational temperature (Mies, 1974; Stubbs et al., 1983; Takahashi et al., 1999) in the following way:

$$
\begin{aligned}
& \mathrm{I}\left(\mathrm{J}^{\prime \prime}, \mathrm{v}^{\prime \prime} \leftarrow \mathrm{J}^{\prime}, \mathrm{v}^{\prime}\right) \\
& \quad=\frac{\mathrm{NA}\left(\mathrm{J}^{\prime \prime}, \mathrm{v}^{\prime \prime} \leftarrow \mathrm{J}^{\prime}, \mathrm{v}^{\prime}\right) 2\left(2 \mathrm{~J}^{\prime}+1\right) \exp \left(-\mathrm{F}\left(\mathrm{J}^{\prime}\right)^{*} \mathrm{hc} / \mathrm{kT}\right)}{\mathrm{Q}_{\mathrm{v}}^{\prime}(\mathrm{T})},
\end{aligned}
$$

where $\mathbf{J}^{\prime}, \mathrm{J}^{\prime \prime}$ are rotational quantum numbers (single primed quantum numbers refer to the upper state, double primed ones to the lower); $\mathrm{v}^{\prime}, \mathrm{v}^{\prime \prime}$ are vibrational quantum numbers; $\mathrm{N}$ is the population of the upper vibrational state; $\mathrm{A}$ $\left(\mathrm{J}^{\prime \prime}, \mathrm{v}^{\prime \prime} \leftarrow \mathrm{J}^{\prime}, \mathrm{v}^{\prime}\right)$ is the Einstein coefficient for the indicated transition; $\mathrm{F}\left(\mathrm{J}^{\prime}\right)$ is the relative value of the energy of the rotational level with $\mathrm{J}=\mathrm{J}^{\prime}$ of the upper vibrational state; $\mathrm{k}$ is the Boltzmann's constant; $\mathrm{T}$ is the rotational temperature; and $\mathrm{Q}_{v^{\prime}}(\mathrm{T})$ is the partition function of the upper vibrational state. The values of Einstein coefficients are taken from Mies (1974) and those of $\mathrm{F}\left(\mathrm{J}^{\prime}\right)$ from Kendall and Clark (1979).

Using Eq. (1) the rotational temperature $\mathrm{T}$ can be determined by comparing the intensities of two or more $\mathrm{OH}$ lines (Mies, 1974; French et al., 2000):

$$
\left.\mathrm{T}=\left[\mathrm{hc} / \mathrm{k}^{*}\left(\mathrm{~F}\left(\mathrm{~J}_{2}\right)-\mathrm{F}\left(\mathrm{J}_{1}\right)\right)\right] / \ln \left[\mathrm{I}_{1} \mathrm{~A}_{2}\left(2 \mathrm{~J}_{2}+1\right)\right\} /\left\{\mathrm{I}_{2} \mathrm{~A}_{1}\left(2 \mathrm{~J}_{1}+1\right)\right\}\right](2)
$$

where $\mathrm{F}\left(\mathrm{J}_{1}\right)$ and $\mathrm{F}\left(\mathrm{J}_{2}\right)$ are the energy levels of the initial rotational states; $I_{1}$ and $I_{2}$ are the emission intensities of the $\mathrm{OH}$ 
KOLHAPUR

April 01 - 02, 2003
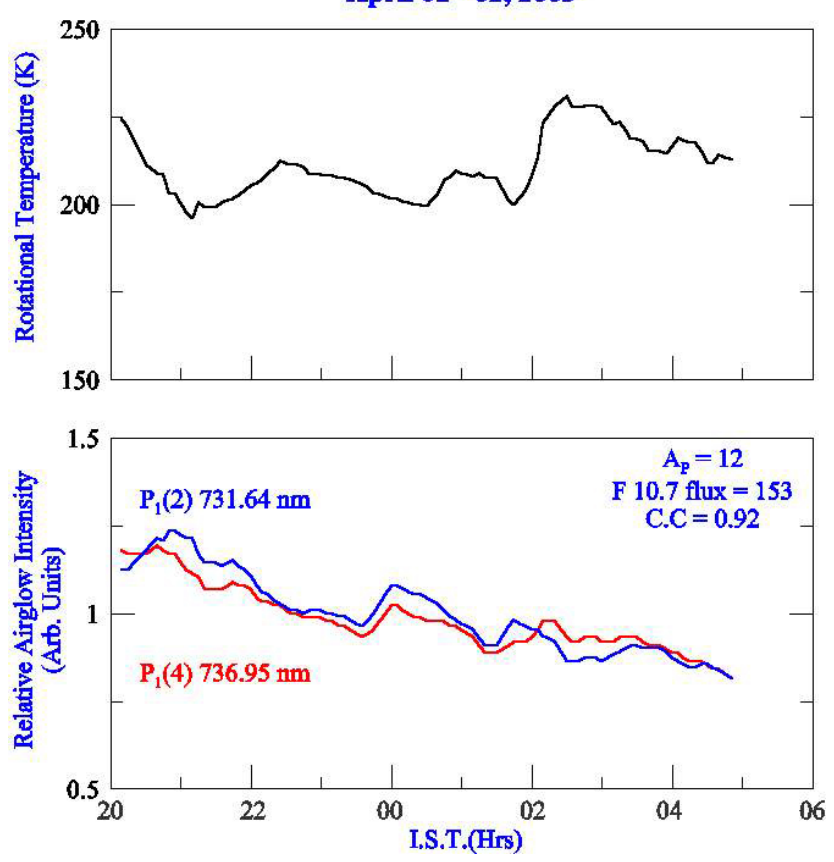

Fig. 1a. The relative intensity of the $\mathrm{P}_{1}(2)$ and $\mathrm{P}_{1}(4)$ lines is shown as well as the rotational temperature calculated from the ratio of the intensity of two lines for the night of 1-2 April 2003 at Kolhapur.

lines from different upper states; $\mathrm{J}_{1}$ and $\mathrm{J}_{2}$ are the upper state, total quantum numbers ; and $\mathrm{h}, \mathrm{c}$ and $\mathrm{k}$ are Planck's constant, the speed of light and Boltzman's constant, respectively.

The intensity ratio between $\mathrm{P}_{1}(2)$ and $\mathrm{P}_{1}(4)$ lines of the $\mathrm{OH}(8,3)$ band were used to obtain rotational temperature using the transition probabilities as given by Mies (1974)(Stubbs et al., 1983).

$\mathrm{T}=207.06 / \ln (2.642 \mathrm{R})$,

where $\mathrm{R}$ is the ratio of the intensities of $\mathrm{P}_{1}(2)$ and $\mathrm{P}_{1}(4)$ lines of the $\mathrm{OH}(8,3)$ band.

\section{Results and discussion}

An initial selection of data for detailed analysis was obtained by rejecting data contaminated by clouds. The intensities were not calibrated due to non-availability of a standard source of light, but efforts are on to calibrate them against a secondary source. Future results would be published after converting them in terms of Rayleighs. The data sets were further scrutinized when good data were recorded for more than four hours in a given night. It was thought that the values of emissions of $\mathrm{P}_{1}(2)$ and $\mathrm{P}_{1}(4)$ lines and the rotational temperature computed can then be meaningful. The relative intensities of the $\mathrm{P}_{1}(2)$ and $\mathrm{P}_{1}(4)$ lines were varying between 4 and 14 units (intensity is measured in arbitrary units).
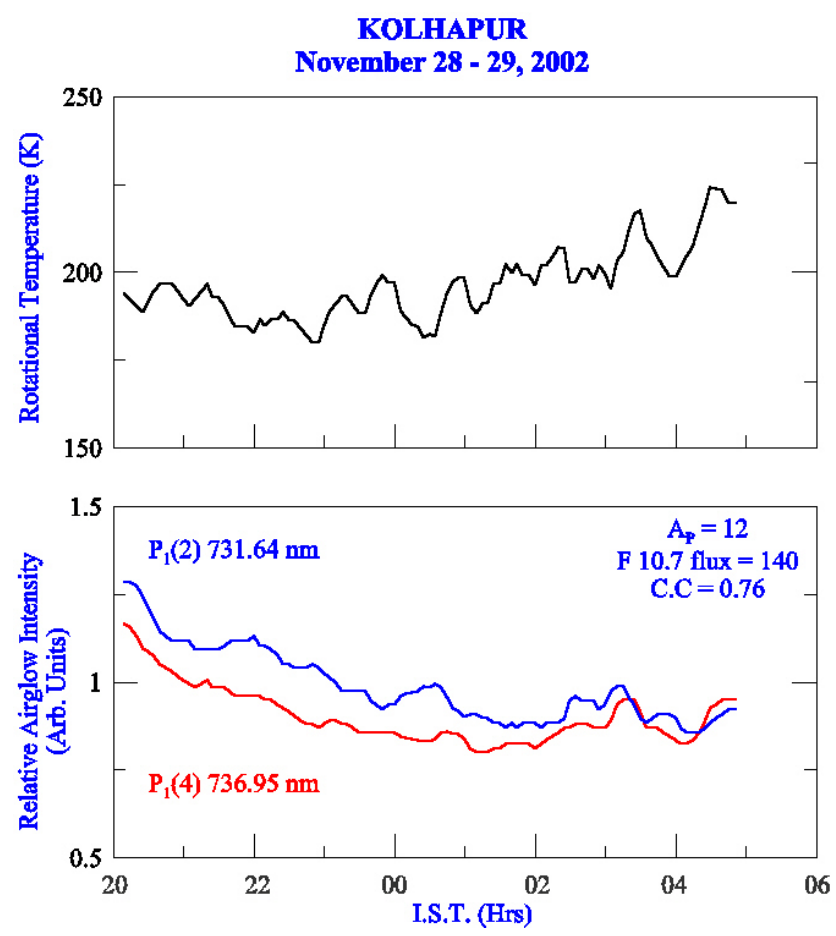

Fig. 1b. Same as Fig. 1a but for 28-29 November 2002.
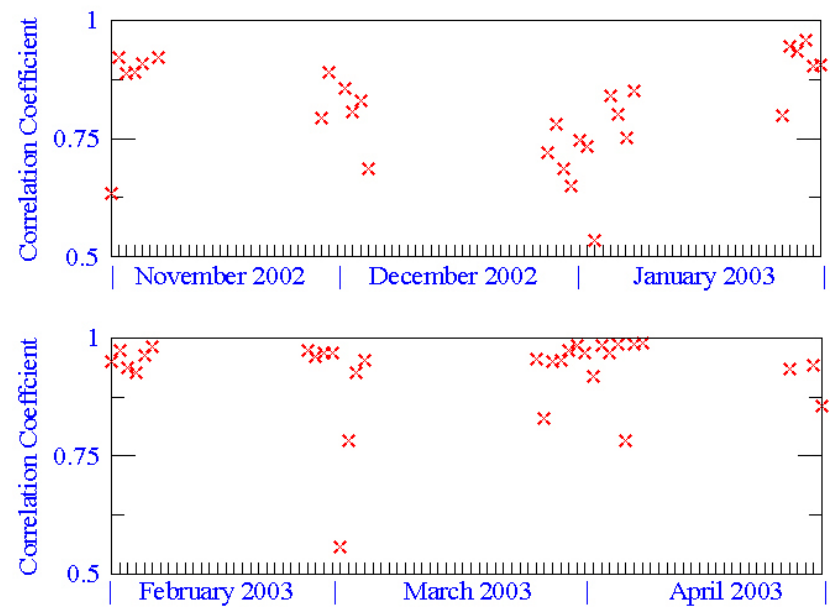

Fig. 2. The values of correlation coefficients between $P_{1}(2)$ and $\mathrm{P}_{1}$ (4) lines of $\mathrm{OH}(8,3)$ band airglow are plotted for different nights during the period of observation.

\subsection{Seasonal and diurnal variation}

The airglow intensity and rotational temperature measurements were carried out at Kolhapur from 1 November 2002 to 29 April 2003 on clear moonless nights. Figure 1a shows an example of the typical variation of relative intensities of the $\mathrm{P}_{1}(2)$ and $\mathrm{P}_{1}(4)$ lines and the rotational temperature computed from the ratio of these two lines for the night of 12 April 2003. Typically, about 110 observations of temperature were recorded during the night. The temperatures vary between 196 to $231 \mathrm{~K}$. Figure $1 \mathrm{~b}$ shows the variation 


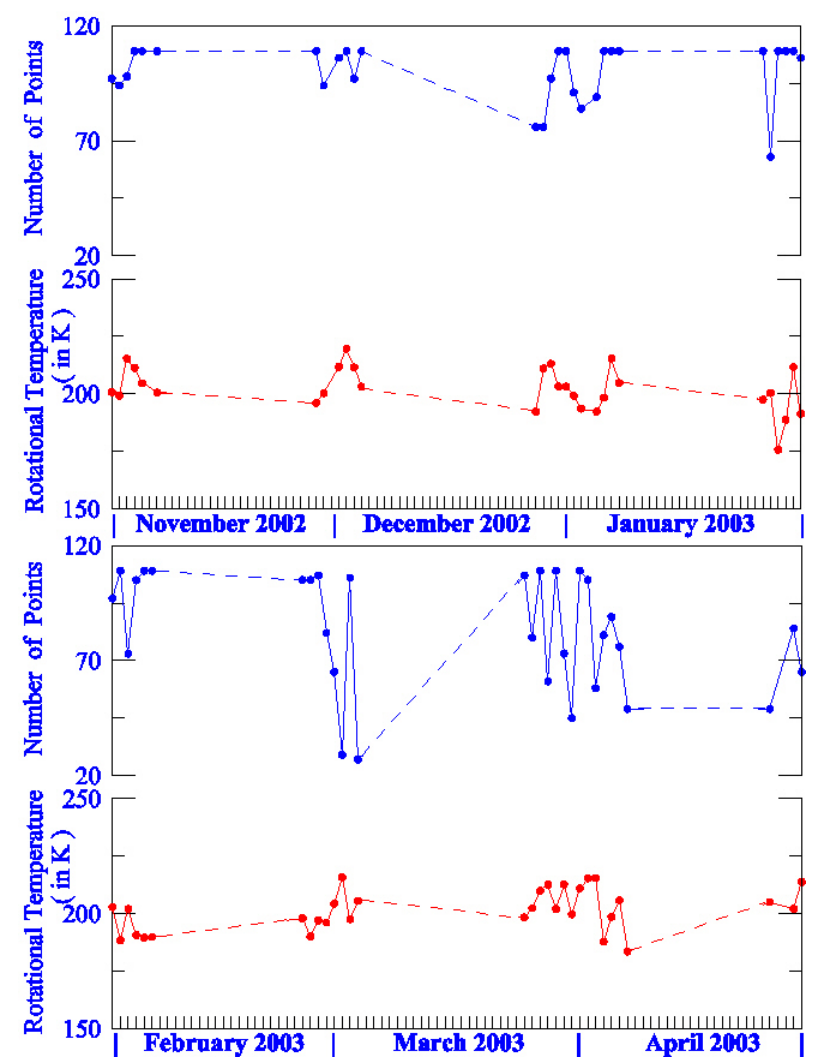

Fig. 3. Mean nightly rotational temperature for the period 1 November 2002 to 29 April 2003. The number of temperature measurements from which each mean is derived is also plotted in the figure.
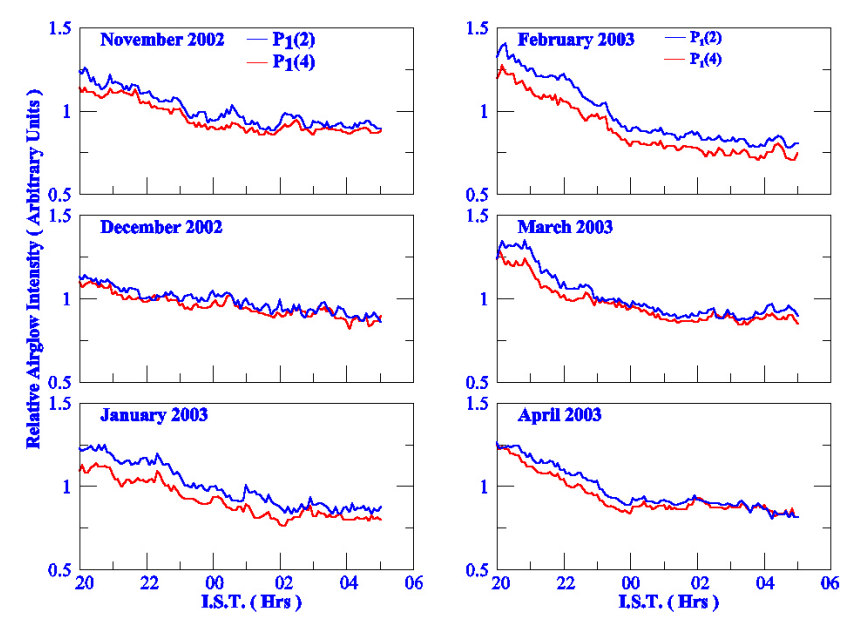

Fig. 4. Mean nocturnal variation of $P_{1}(2)$ and $P_{1}(4)$ intensity of $\mathrm{OH}(8,3)$ band for different months at Kolhapur during 2002-2003.

of intensities of $\mathrm{P}_{1}(2)$ and $\mathrm{P}_{1}(4)$ lines and the temperature on the night of 28-29 November 2002. Typically temperature data shows periodicities of about one hour. The correlation coefficients between the relative intensities of the $\mathrm{P}_{1}(2)$ and $\mathrm{P}_{1}(4)$ lines are shown in Fig. 2. For most of the nights the correlations ( 0.54 to 0.98 ) between $\mathrm{P}_{1}(2)$ and $\mathrm{P}_{1}(4)$ lines are very good. All temperature and band intensity val-
Table 1. Nights of observation and their monthly mean temperature.

\begin{tabular}{cccc}
\hline Month & $\begin{array}{c}\text { Total no. } \\
\text { of nights }\end{array}$ & $\begin{array}{c}\text { Monthly mean } \\
\text { temperature (K) }\end{array}$ & $\begin{array}{c}\text { Standard } \\
\text { Deviation } \pm \Delta \mathrm{K}\end{array}$ \\
\hline Nov. 2002 & 8 & 203.51 & \pm 13.02 \\
\hline Dec. 2002 & 9 & 207.94 & \pm 18.13 \\
\hline Jan. 2003 & 12 & 197.44 & \pm 19.37 \\
\hline Feb. 2003 & 10 & 194.05 & \pm 10.96 \\
\hline Mar. 2003 & 11 & 204.47 & \pm 12.29 \\
\hline Apr. 2003 & 10 & 204.63 & \pm 14.17 \\
\hline Total & 60 & 202.01 & \pm 14.66 \\
\hline
\end{tabular}

Table 2. The observed mean temperature at low-latitude stations using photometric ground-based measurements.

\begin{tabular}{cccc}
\hline $\begin{array}{c}\text { Year of } \\
\text { Measurements }\end{array}$ & Latitude & $\begin{array}{c}\text { Temperature } \\
\mathrm{K}\end{array}$ & Reference \\
\hline $1972-1973$ & $23^{\circ} \mathrm{S}$ & 179 & Takahashi et al. (1977) \\
\hline $1974-1975$ & $24^{\circ} \mathrm{N}$ & $180-200$ & Majmudar (1977) \\
\hline 1980 & $18^{\circ} \mathrm{N}$ & $170-270$ & Tepley et al. (1981) \\
\hline $1977-1982$ & $23^{\circ} \mathrm{S}$ & $185-200$ & Takahashi et al. (1984) \\
\hline 1985 & $23^{\circ} \mathrm{S}$ & 190 & Takahashi et al. (1986) \\
\hline $1985-1986$ & $18^{\circ} \mathrm{N}$ & $188-205$ & Agashe et al. (1989) \\
\hline $2002-2003$ & $16.8^{\circ} \mathrm{N}$ & $202 \pm 15$ & Present Study (2002-2003) \\
\hline
\end{tabular}

ues were computed using Mies (1974) transition probabilities for comparison of our results with other low latitude measurements (Takahashi et al., 1999). The absolute values of derived rotational temperatures are dependent on transition probabilities $A_{1}$ and $A_{2}$, as given in Eq. (2). We also calculated temperatures using coefficients tabulated by Turnbull and Lowe (1989) and Langhoff et al. (1986). But the differences were small. The variation of mean nightly rotational temperature over 6 months is shown in Fig. 3. The range of variation of temperature for a particular month is small. The number of points used to compute the rotational temperature at a particular night is also shown in the figure. To examine whether any diurnal trend exists in the data, hourly mean values of rotational temperature are computed as a function of local time (IST) for different months.

Table 1 summarizes the nights of observation whose data have been included in this paper. The monthly mean temperature in different months is shown in Table 1. It has been found that the mean temperature of the mesopause at Kolhapur from all the measurements was around $202 \pm 15 \mathrm{~K}$. The result compares well with the other low-latitude measurements of rotational temperature as given in Table 2. In Fig. 4, 


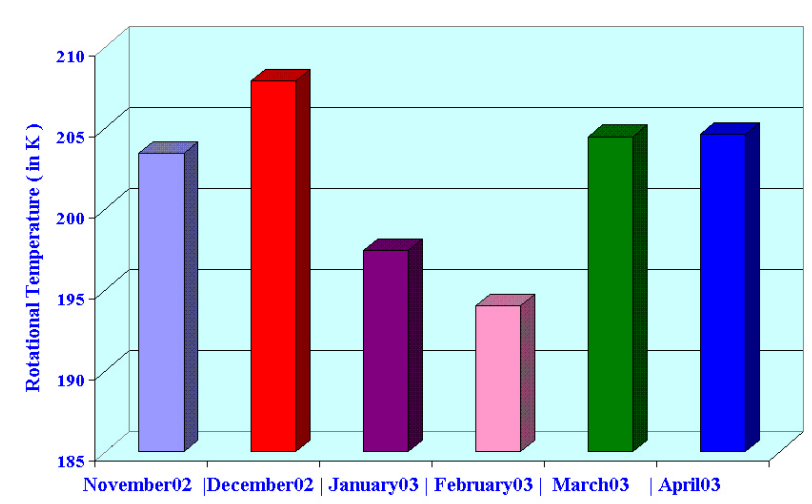

Fig. 5. Monthly mean rotational temperature observed at Kolhapur during November 2002 to April 2003.

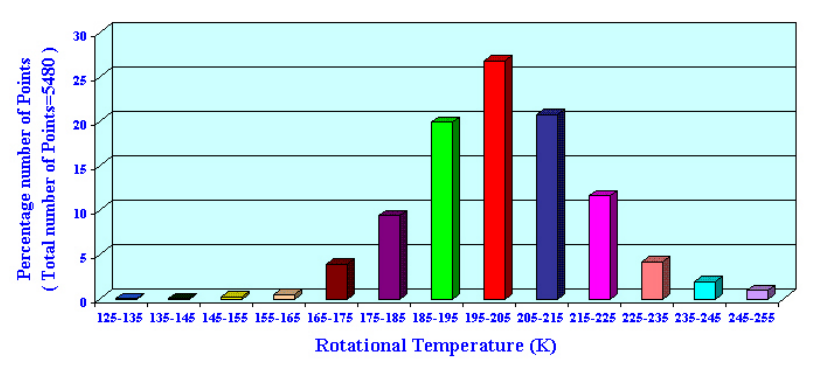

Fig. 6. Frequency of occurrence of mesopause temperature measurements at Kolhapur in $10 \mathrm{~K}$ interval over the period 2 November 2002-29 April 2003.

we show the nocturnal monthly average variation of the intensity of the $\mathrm{P}_{1}(2)$ and $\mathrm{P}_{1}(4)$ lines of $\mathrm{OH}(8,3)$ Meinel Band for each month at Kolhapur. In general, a steady decrease in intensity during the night has been observed in most of the months. It is more during the early night and decreases towards dawn, as shown in the figure. This seems to be in good agreement with earlier reports. This has been explained due to decreasing concentrations of hydrogen and odd oxygen as a result of the absence of photolysis of $\mathrm{O}_{2}$ and $\mathrm{H}_{2} \mathrm{O}$ (Abreu and Yee, 1989; Mulligan et al., 1995).

The monthly mean temperature in different months is shown in Fig. 5 by a bar graph. It is to be noted that there is a decrease in temperature during January and February compared to other months. The average monthly temperature remains almost constant during March and April months, slightly lower in November. We found the temperature to be maximum around $208 \mathrm{~K}$ during the December month and minimum about $194 \mathrm{~K}$ during February 2003.

The data are also analysed into temperature intervals of $10 \mathrm{~K}$ to examine the distribution of the rotational temperature. Figure 6 shows the results of the distribution for the periods 1 November 2002 to 29 April 2003. It is seen that $27 \%$ of temperatures lie in the range $195-205 \mathrm{~K}$. Of all the temperature points considered (the total number of points $=5480$ ) about $20 \%$ and $20.7 \%$ of the points lie in the temperature

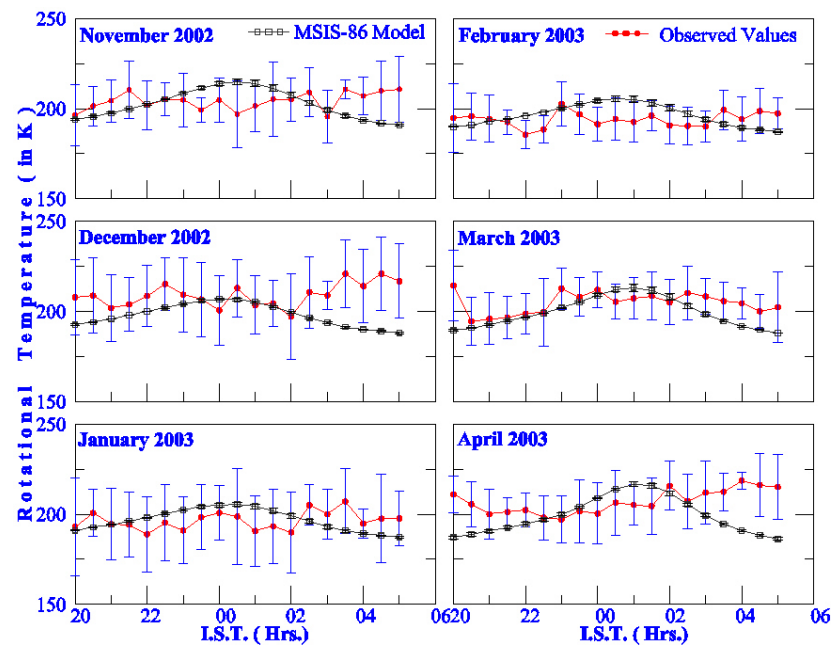

Fig. 7. Half-hourly means of the measured rotational temperature over the period 2 November 2002 to 29 April 2003. The vertical arrows show the standard deviation ( \pm sigma) in the observed values. Temperature parameters computed from MSIS (1986) model are also depicted in the figure for the corresponding period.

range $185-195^{\circ} \mathrm{K}$ and $205-215^{\circ} \mathrm{K}$. Thus, more than $67 \%$ of the points lay in the temperature range $185-215^{\circ} \mathrm{K}$ range. Hence, it can be interpreted that the temperature near the mesopause over Kolhapur generally varies in the range 185$215^{\circ} \mathrm{K}$.

\subsection{Comparisons with model}

The measured rotational temperature were compared with the temperature derived from the MSIS- 86 model. The Mass Spectrometer Incoherent Scatter (MSIS) model describes the neutral temperature and the densities in the upper atmosphere. This model is based on the extensive data compilation and analysis work of A. E. Hedin and his colleagues (Hedin, 1987). Data sources include measurements from several rockets, satellites and incoherent scatter radars. This model expects as input - year, day of year, universal time, altitude, geodetic latitude and longitude, local apparent solar time, solar F10.7 flux (for previous day and three-month average), and a magnetic $\mathrm{A}_{P}$ index (daily or $\mathrm{A}_{P}$ history for last $59 \mathrm{~h}$ ). For these conditions the following output parameters are calculated: number density of $\mathrm{He}, \mathrm{O}, \mathrm{N}_{2}, \mathrm{O}_{2}, \mathrm{Ar}, \mathrm{H}$ and $\mathrm{N}$, the total mass density; neutral temperature and exospheric temperature. The results of this analysis are shown in Fig.7. The mean rotational temperature parameters were computed at every half an hour for each month starting at 20:00 $\mathrm{h}$ in the evening to $05: 00 \mathrm{~h}$ in the morning. The vertical arrows show the error bars which are the standard deviation of the observed values of rotational temperature. The model values generally show their peaks around local midnight on every month. The observed values of rotational temperature are found to be more compared to their model estimates from 02:00 to 05:00 h during most of the months. In general, the agreement between the model estimates and 
the observed mesopause temperature are good within the error bar in the first half of the nights. Jonsson et al. (2002) presented a comparison between the Canadian Middle Atmosphere Model (CMAM) and 9 years of HALOE temperature measurements for the middle atmosphere. The analysis showed an overall agreement throughout the entire middle atmosphere with discrepancies $10 \mathrm{~K}$ and less on various areas for both equinox and solstice conditions.

\section{Conclusions}

In comparison with other methods for observation of this geophysical quantity (rotational temperature), the optical technique is inexpensive and readily applicable for observation over a long period of time. The data were presented for 60 clear nights. The salient features of the observation are summarized below:

1. The correlation between $\mathrm{P}_{1}(2)$ and $\mathrm{P}_{1}(4)$ line intensities on large number of nights is very good.

2. The rotational temperature data obtained from the ratio of $\mathrm{P}_{1}(2)$ and $\mathrm{P}_{1}(4)$ lines are in good agreement during most parts of the night with the results obtained from the MSIS- 86 model.

3. The $\mathrm{P}_{1}(2)$ and $\mathrm{P}_{1}(4)$ line intensities of $\mathrm{OH}(8,3)$ band during November 2002-April 2003 at Kolhapur, a lowlatitude station, showed a steady decrease from evening to dawn hours. It is more during the early night and it decreases towards dawn. This seems to be in good agreement with earlier reports. This has been explained due to decreasing concentrations of hydrogen and odd oxygen as a result of absence of photolysis of $\mathrm{O}_{2}$ and $\mathrm{H}_{2} \mathrm{O}$ (Abreu and Yee, 1989) at night.

4. Results of $\mathrm{OH}$ temperature measurements match well with earlier low latitude measurements of $\mathrm{OH}$ rotational temperature. There is a great variability in the diurnal behavior in low and mid latitudes. There are four different types of nocturnal variations of temperature as observed by Agashe et al. (1989) at a low-latitude station, Pune $\left(18^{\circ} \mathrm{N}, 73^{\circ} \mathrm{E}\right)$ in India. The monthly mean temperature of the mesopause region over Pune was found to be $195 \pm 10 \mathrm{~K}$. The temperature was found to be higher in winter than in summer. From the analysis of results, it has been found that monthly mean temperature of near the mesopause region over Kolhapur was $202 \pm 15 \mathrm{~K}$. Changes in temperature during a night could be attributed to changes in layer altitude on some occasions while on other occasions the changes show the influence of gravity waves.

5. All temperature and band intensity values were computed using Mies (1974) transition probabilities in order to compare with other low-latitude measurements. We also calculated temperatures using coefficients tabulated by Turnbull and Lowe (1989), Langhoff et al. (1986). But the differences were less than 5-10 K.
6. There are reports showing the seasonal (monthly) variation of rotational temperature maximizing during winter and minimizing during summer. This has been explained in terms of transport of atomic oxygen from summer hemisphere to the winter hemisphere. However, Takahashi et al. (1984) reported a summer maxima and a winter minima at $23^{\circ} \mathrm{S}$ latitude. We found our temperature measurement to be maximum during December and minimum during February 2003. Thus, it is clear that the ground-based $\mathrm{OH}$ airglow technique can be used as a remote sensing tool to study the mesopause dynamics.

Acknowledgements. The airglow measurements are carried out under the scientific collaboration between IIG, Navi Mumbai and Shivaji University, Kolhapur. The tilting-filter photometers were provided by P. L. Dyson, La Trobe Univerity, Melbourne, Australia under Indo-Australia agreement on Science and Technology. The funds for research on studies of the upper atmosphere in IIG are provided by Department of Science and Technology (DST), Govt. of India, New Delhi. Technical support received from P. T. Patil in Airglow work is gratefully acknowledged.

Topical Editor U.-P. Hoppe thanks two referees for their help in evaluating this paper.

\section{References}

Abreu, V. J. and Yee, J. H.: Diurnal and seasonal variation of the night time $\mathrm{OH}(8,3)$ emission at low latitudes, J. Geophys. Res., 94, 11949-11957, 1989.

Agashe, V. V. and Gurao, J. B.: Intensity Variation of $\mathrm{OH}$ Meinel Bands in the nightglow, Ind. J. Radio and Space Phys., 6, 322324, 1977.

Agashe, V. V., Pawar, V. R., Aher, G. R., Nighut, D. N., and Jehangir, A.: Study of mesopause temperature and its behavior from OH nightglow, Ind. J. Radio and Space Phys., 18, 309-314, 1989.

French, W. J. R., Burns, G. B., Finlayson, K., Greet, P. A., Lowe, R. P., and Williams, P. F. B.: Hydroxyl(6-2) airglow emission intensity ratios for rotational temperature determination, Ann. Geophys., 18, 1293-1303, 2000.

Greet, P. A., French, W. J. R., Burns, G. B., Williams, P. F. W., Lowe, R. P., and Finlyson, K.: OH(6-2) Spectra and rotational temperature measurements at Davis, Antarctica, Ann. Geophys., 16, 77-89, 1998.

Hedin, A. E.: MSIS-86 Thermospheric Model, J. Geophys. Res., 92, 4649-4662, 1987.

Hobbs, B. G., Reid, I. M., and Greet, P. A.: Mesospheric Rotational Temperatures from the $\mathrm{OH}(6-2)$ emissions above Adelaide, Australia, J. Atmos. Terr. Phys., 58, 12, 1337-1341, 1996.

Jonsson, A., de Grandepre, J., and McConnell, J. C.: A comparison of mesospheric temperature from Canadian Middle Atmosphere Model and haloe observations: Zonal mean and signature of the solar diurnal tide, Geophys. Res. Lett., 29 (9), 10 1029-10 1033, 2002.

Kendall, D. J. W. and Clark, T. A.: The pure rotational atmospheric lines of hydroxyl, J. Quant Spectrosc. Radiat Transfer, 21, 511518, 1979. 
Kubota, M., Ishi, M., Shiokawa, K., Ejiri, M. K., and Ogawa, T.: Height measurements of nightglow structures observed by allsky imagers, Adv. Space Res., 24, 593-596, 1999.

Langhoff, S. R., Werner, H. J., and Rosmus, P.: Theoretical transition probabilities for the $\mathrm{OH}$ Meinel system, J. Mol. Spectr., 118, 507-529, 1986.

Majmudar, N. H.: Study of the upper atmosphere by $\mathrm{OH}$ and other airglow emissions, Ph.D. Thesis, M. S. University of Baroda, Baroda, 1977.

Meinel, A. B.: $\mathrm{OH}$ emission bands in the spectrum of night sky, Astrophys. J., 111, 555-564, 1950.

Meriwether, J. W.: High latitude airglow observations of correlated short term fluctuations in the hydroxyl Meinel 8-3 band intensity and rotational temperature, Planet. Space Sci., 23, 1211-1221, 1975.

Meriwether, J. W., Hays, P. B., McWalters, K. W., and Nagy, A. F.: Interferometric measurements of the 7319 A doublet emission of OH, Planet. Space Sci., 22, 636-644, 1974.

Mies, F. H.: Calculated vibrational probabilities of $\mathrm{OH}\left(\mathrm{X}^{2} \mathrm{II}\right), \mathrm{J}$. Molec. Spectros., 53, 150-180, 1974.

Mukherjee, G. K. and Dyson, P. L.: A filter tilting photometer for nightglow measurements of $630.0 \mathrm{~nm}$ emission line, Ind. J. Radio Space Phys., 21, 212-217, 1992.

Myrabo, H. K.: Temperature variation at mesopause levels during winter solstice at $78^{\circ}$ N, Planet. Space Sci., 32, 249-255, 1984.

Mulligan, F. I., Horgan, D. F., Galligan, J. G., and Griffin, E. M.: Mesopause temperature and intensity band brightness calculated from airglow $\mathrm{OH}$ emissions recorded at Maynooth $\left(53.2^{\circ} \mathrm{N}\right.$, 6.4 W), J. Atmos. Terr. Phys., 57 (13), 1623-1637, 1995.

Roble, R. G. and Dickinson, R. E.: How will changes in carbon dioxide and methane modify the mean structure of mesosphere and thermosphere, Geophys. Res. Lett., 16, 1441-1444, 1989.

Schaffer, R. C. and Fastie, W. G.: Tilting photometer measurements in dayglow rocket photometry, Appl. Opt., 11, 2289-2295, 1972.

Stubbs, L. C., Boyd, J. S., and Bond, F. R.: Measurement of the $\mathrm{OH}$ rotational temperature at Mawson, East Antarctica, Planet. Space Sci., 31 (8), 923-932, 1983.

Sivjee, G. G. and Hamwey, R. M.: Temperature and chemistry of the polar mesopause OH, J. Geophys. Res., 92, 4663-4672, 1987.
Sivjee, G. G., Dick, K. A., and Feldman, P. D.: Temporal variation in night-time Hydroxyl rotational temperatue, Planet. Space Sci., 20, 261-269, 1972.

Takahashi, H. and Batista, P. P.: Simultaneous measurements of $\mathrm{OH}(9,4),(8,3),(7,2),(6,2)$ and $(5,1)$ bands in the airglow, J. Geophys. Res., 86, 5632-5642, 1981.

Takahashi, H., Clemsha, B. R., and Sahai, Y.: Nightglow $\mathrm{OH}(8,3)$ band intensities and rotational temperature at $23^{\circ} \mathrm{S}$, Planet. Space Sci., 22, 1323-1329, 1974.

Takahashi, H., Sahai, Y., Clemsha, B. R., Batista, P. P., and Teixeira, N. R.: New hydroxyl transition probabilities and their importance in airglow studies, Planet. Space Sci., 25, 541-548, 1977.

Takahashi, H., Sahai, Y., and Batista, P. P.: Tidal and Solar cycle effects on the $\mathrm{OI} 5577 \mathrm{~A} \mathrm{NaD}$ and $\mathrm{OH}(8,3)$ airglow emission observed at $23^{\circ}$ S, Planet. Space Sci., 32, 897-902, 1984.

Takahashi, H., Sahai, Y., and Batista, P. P.: Airglow $\mathrm{O}_{2}\left({ }^{1} \sum\right)$ Atmospheric band at $8645 \mathrm{~A}$ and the rotational temperature observed at $23^{\circ} \mathrm{S}$, Planet. Space Sci., 34, 301-306, 1986.

Takahashi, H., Batista, P. P., Buriti, R. A., Gobbi, D., Nakamura, T., Tsuda, T., and Fukao, S.: Response of the airglow $\mathrm{OH}$ emission temperature and mesopause wind to the atmospheric wave propagation over Shigaraki, Japan, Earth Planets Space, 51, 863-875, 1999.

Tepley, C. A., Burnside, R. G., and Meriwether Jr., J. W.: Horizontal thermal structure of the mesosphere from observations of $\mathrm{OH}(8,3)$ band emissions, Planet. Space Sci.,29, 1241-1249, 1981.

Turnbull, D. N. and Lowe, R. P.: New hydroxyl transitional probabilities and their importance in airglow studies, Planet. Space Sci., 37, 723-738, 1989.

Watanabe, T. and Nakamura, M.: Rocket measurements of $\mathrm{O}_{2}$ and OH Meinel Bands in the Airglow, J. Geophys. Res., 86, A7, 5768-5774, 1981.

Wiens, R. H.: Diurnal variation of the $(8,3) /(5,0)$ intensity ratio of nightglow $\mathrm{OH}$ at Adi Ugri, Planet. Space Sci., 22, 1059-1067, 1974.

Wiens, R. H. and Weill, G.: Diurnal, annual and solar cycle variations of hydroxyl and sodium night glow intensities in the Europe-Africa sector, Planet. Space Sci., 21, 1011-1027, 1973.

Williams, P. F. B.: OH rotational temperatures at Davis, Antarctica, via scanning spectrometer, J. Geophys. Res., 44, 163-170, 1996. 